\author{
Mariusz FILIPOWICZ ${ }^{1}$ \\ Mateusz SZUBEL ${ }^{2}$ \\ Krzysztof SORNEK ${ }^{3}$ \\ Estera BOŻEK ${ }^{4}$ \\ Leszek KURCZ \\ Arkadiusz FIGÓRSKI ${ }^{6}$ \\ Wiktor WESOLOWSKI ${ }^{7}$ \\ Jacek RECAA ${ }^{8}$
}

\title{
BADANIA ENERGETYCZNYCH \\ I EKOLOGICZNYCH PARAMETRÓW PRACY DOMOWYCH URZĄDZEŃ GRZEWCZYCH TYPU PIECOKOMINKI
}

\begin{abstract}
W ostatnich latach obserwujemy dynamiczny rozwój systemów grzewczych opartych na różnorodnych rozwiązaniach technicznych (paliwa, układach wytwarzania i oddawania ciepła, systemy sterowania). Systemy te jednak nie wyparły tradycyjnych urządzeń grzewczych, których historia sięga czasów Imperium Rzymskiego i wcześniej. Te systemy to tradycyjne paleniska reprezentowane obecnie przez piece kaflowe, kominki, czy ich kombinacje - piecokominki. Można wręcz stwierdzić, że obecnie obserwujemy renesans tych urządzeń, łączących elementy ozdobne oraz użytkowe. Nie bez znaczenia jest fakt, że można zaliczyć je do odnawialnych źródeł energii zasilanych biomasą. Względy ekologiczne są o tyle istotne bowiem coraz większą popularność zyskują hasła zakazania spalania paliw
\end{abstract}

\footnotetext{
${ }^{1}$ Autor do korespondencji: Mariusz Filipowicz, AGH Akademia Górniczo-Hutnicza, Wydział Energetyki i Paliw, al. Mickiewicza 30, 30-059 Kraków, Tel. 604 921-688, filipow@ agh.edu.pl

${ }^{2}$ Mateusz Szubel, AGH Akademia Górniczo-Hutnicza, Wydział Energetyki i Paliw, al. Mickiewicza 30, 30-059 Kraków, 012 617-34-28, mszubel@ agh.edu.pl

${ }^{3}$ Krzysztof Sornek, AGH Akademia Górniczo-Hutnicza, Wydział Energetyki i Paliw, al. Mickiewicza 30, 30-059 Kraków, 012617 50-94, ksornek@agh.edu.pl

${ }^{4}$ Estera Bożek, AGH Akademia Górniczo-Hutnicza, Wydział Energetyki i Paliw, al. Mickiewicza 30, 30-059 Kraków, 012617 34-28, ebozek@agh.edu.pl

${ }^{5}$ Leszek Kurcz, AGH Akademia Górniczo-Hutnicza, Wydział Energetyki i Paliw, al. Mickiewicza 30, 30-059 Kraków, 017 38-22, kurcz@agh.edu.pl

${ }^{6}$ Arkadiusz Figórski, AGH Akademia Górniczo-Hutnicza, Wydział Energetyki i Paliw, al. Mickiewicza 30, 30-059 Kraków, 012617 51-84, figorski@agh.edu.pl

${ }^{7}$ Wiktor Wesołowski, AGH Akademia Górniczo-Hutnicza, Wydział Energetyki i Paliw, al. Mickiewicza 30, 30-059 Kraków, 012617 34-28, wikiwesol@gmail.com

8 Jacek Ręka, CEBUD S.C., ul. Balicka 320, 30-198 Kraków, Tel. 012 637-36-23, cebud@ cebud.eu
} 
współpracy z przedstawicielem rzemiosła podjęto prace nad tymi urządzeniami mając na uwadze dokładne zobrazowanie ich parametrów, możliwości opracowania systemów sterowania czy wreszcie wprowadzenie szeregu innowacji do ich pracy. Niniejszy artykuł prezentuje przykłady i uwagi na temat wyników otrzymanych podczas pierwszego etapu badań $\mathrm{w}$ ramach realizowanego projektu. Przedstawiono opis stanowiska badawczego oraz wyniki wybranych pomiarów. Wykonano pomiary temperatury w komorze spalania i ciągu spalinowym układu, analizę podstawowych składników spalin w zależności od regulacji dopływu powietrza do komory spalania. Szybkość ubytku paliwa w komorze spalania w trakcie spalania i widmo płomienia uzupełniły zbiór otrzymanych danych. Wyniki te, poddane odpowiedniej analizie, mają pozwolić na opracowanie efektywnego sterowania pracą urządzenia w celu uzyskania maksymalizacji sprawności i minimalizacji emisji z paleniska.

Słowa kluczowe: piecokominek, analiza spalin, sterowanie spalaniem, efektywność energetyczna, biomasa, drewno

\section{Wstęp}

Od chwili kiedy ogień na trwale znalazł sobie miejsce we wnętrzach budynków nastąpił rozwój różnych systemów grzewczych opartych na spalaniu drewna i innej biomasy. Historycznym przykładem może być m.in. hypocaustum (rodzaj ogrzewania podłogowego) stosowany na terenie Imperium Rzymskiego już przed narodzinami Chrystusa. Piec umieszony pod podłogą i system kanałów pozwalał efektywnie rozprowadzać ciepłe powietrze.

Obecnie tradycyjne systemy ogrzewania charakteryzują się prostotą konstrukcji, niezbyt zaawansowanym systemami sterowania, względnie niskimi kosztami przy jednocześnie dość dobrych parametrach grzewczych. Na naszych szerokościach geograficznych typowy kominek służy głównie jako dodatkowe źródło ciepła. Ponadto w polskim prawie budowlanym zabrania się użytkowania kominka jako jedynego źródła ciepła. Łącząc funkcjonalnie i konstrukcyjnie piece kaflowe z kominkiem, otrzymujemy bardzo ciekawe rozwiązanie tzw. piecokominek.

Wśród omawianych urządzeń możemy wyróżnić [1]:

- piece tradycyjne,

- piece współczesne (tzw. piecokominki),

- piece współczesne z dodatkowymi wymiennikami ciepła,

- kominki,

- kominki z wymiennikami ciepła.

Schemat budowy pieca tradycyjnego i współczesnego przedstawiony jest na rysunku 1 a i b. Widoczna jest komora spalania (palenisko tradycyjne, murowane $\mathrm{z}$ cegieł lub prostek szamotowych). W piecach współczesnych może to też być odpowiedni wkład (stalowy lub żeliwny) lub gotowe palenisko prefabrykowane. Spaliny bezpośrednio po opuszczeniu komory spalania posiadaja 
wysoką temperaturę (nawet do $1000^{\circ} \mathrm{C}$ ) i kierowane są przez czopuch do odpowiedniego układu akumulacyjnego wymiennika ciepła z elementów ceramicznych, przepływając przez nie, ogrzewają je i w ten sposób się ochładzają, ochłodzone docierają do komina. Natomiast ogrzane od wewnątrz elementy ceramiczne oddają swoje ciepło do pomieszczenia.

Istotną rolę w tym systemie odgrywają tzw. akumulacyjne wymienniki ciepła, tradycyjnie budowane z cegieł lub prostek szamotowych lub ceramiczne moduły akumulacyjne (np. CMA), które stanowią wymiennik typu spaliny-materiał akumulacyjny.

Akumulacja ciepła we współczesnych piecach odbywa się za pomocą następujących materiałów:

- tradycyjny szamot,

- specjalny rodzaj ogniotrwałego betonu szamotowego - np. polski Akubet;

w postaci elementów takich jak:

- ceramiczne moduły akumulacyjnych wymienników ciepła (CMA),

- ceramiczne płyty akumulacyjne zewnętrznego płaszcza grzewczego (CPA) płyty stworzone z szamotowej masy akubetowej, dzięki małej grubości bardzo dobrze nadają się do budowy różnego rodzaju elementów konstrukcyjnych, dużych powierzchni grzewczych, a także zewnętrznego płaszcza kominka; wykonywane są również płyty łukowe oraz kątowe,

- gotowe prefabrykowane paleniska akumulacyjne.

a)
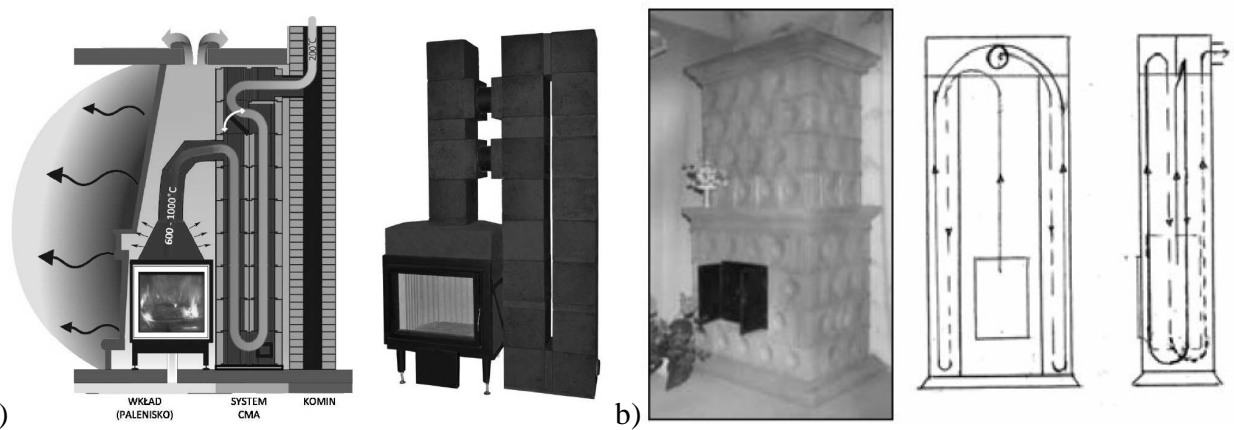

Rys. 1. Schemat działania i wizualizacja a) piecokominka, b) tradycyjnego pieca kaflowego, na podstawie [2]

Fig. 1. Diagram and visualization of a) a fireplace with the heat accumulation system, b) a traditional tiled stove, based on [2]

Celem zapewnienia optymalnej pracy energetycznej i ekologicznej należy rozwiązać szereg problemów technicznych, są to m.in.:

- zapewnienie odpowiednich warunków spalania w komorze poprzez dostarczanie odpowiedniej ilości powietrza i właściwe rozprowadzenie w niej tego powietrza, 
- stosowanie odpowiednich materiałów akumulujących ciepło, dobór kanałów spalinowych o odpowiedniej długości i przekroju oraz optymalizacja ich masy,

- ograniczenie emisji zanieczyszczeń gazowych i pyłów, wymagane jest tutaj m.in. stosowanie paliwa o odpowiednich parametrach,

- sposób dostosowania do warunków i potrzeb grzewczych użytkownika, mocy grzewczej i okresu grzewczego,

- stworzenie odpowiednich algorytmów sterowania - jest to istotne dla każdego z ww. zagadnień.

Ważność powyższych zagadnień potwierdza analiza specjalistycznej literatury (np. pozycje [3-5]), w których opisano szereg innowacyjnych prac podjętych na tego typu układach grzewczych. Przedstawiono założenia i wyniki zaawansowanych numerycznych symulacji z użyciem oprogramowania typu CFD, prace nad wykorzystaniem zaawansowanych czujników gazu do sterowania procesem spalania, czy sposoby zmniejszenia emisji zanieczyszczeń poprzez wykorzystanie katalizatorów. Liderem badań w tym zakresie są ośrodki z Austrii oraz Niemiec. W tych krajach mocno rozwija się rynek tego typu urządzeń, a badania naukowe są stymulowane przez wprowadzanie coraz ostrzejszych norm ochrony środowiska, co w przeciwieństwie do zakazów spalania danego paliwa ma głęboki sens, gdyż środowiska nie zanieczyszcza paliwo samo w sobie, a to co się wydostaje z komina jako rezultat procesu spalania.

\section{Opis przeprowadzonych badań}

\subsection{Stanowisko badawcze}

Widok stanowiska badawczego przedstawiony jest na rysunku 2 oraz 3 . Podstawowe jego elementy to: układ piecokominka (akumulacyjna komora spalania z modułami akumulującymi ciepło), tensometryczna waga podestowa, zestaw czujników, analizator spalin, kanały dolotowe powietrza z przepustnicami, układ kontrolno-pomiarowy i komputer. W pomiarach wykorzystywano również kamerę termowizyjną i spektrometr optyczny.

\subsection{Układ kontrolno-pomiarowy}

Jednostką centralną jest sterownik programowalny PLC (oparty na systemie WAGO 750) wraz z odpowiednimi modułami we/wy. Programowanie odbywa się z wykorzystaniem środowiska CoDeSys, co pozwala na elastyczne konfigurowanie układu w zależności od potrzeb.

Układ kontrolno-pomiarowy zbiera dane z czujników pomiarowych temperatury ulokowanych we wnętrzu komory spalania i na powierzchni elementów akumulujących ciepło, przetwornika prędkości przepływu powietrza, analizatora spalin oraz podaje sygnały sterujące dla trzech przepustnic powietrza. 

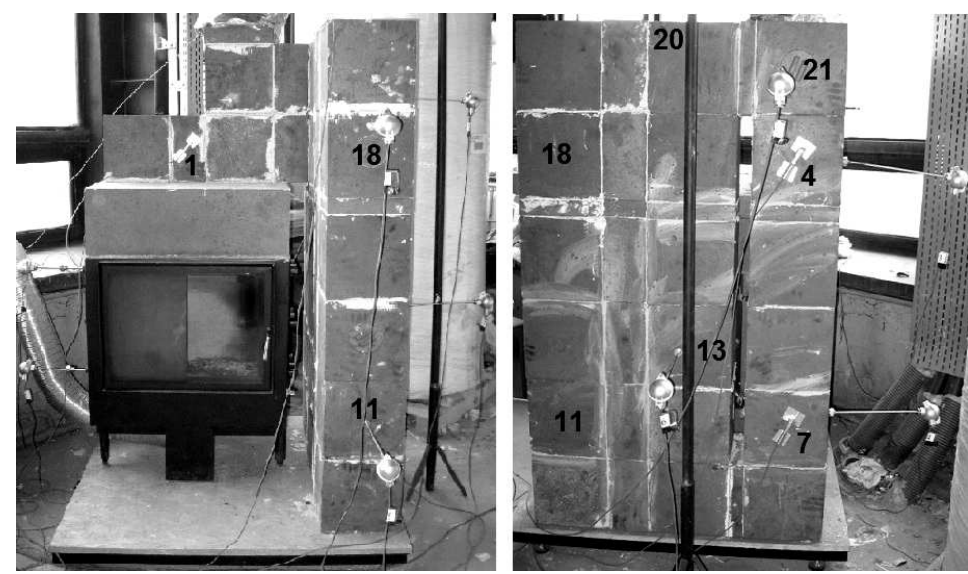

Rys. 2. Zdjęcie stanowiska badawczego z usytuowaniem czujników pomiarowych w wybranych punktach

Fig. 2. Photo of the experimental set-up, the sensors located in the selected points are visible

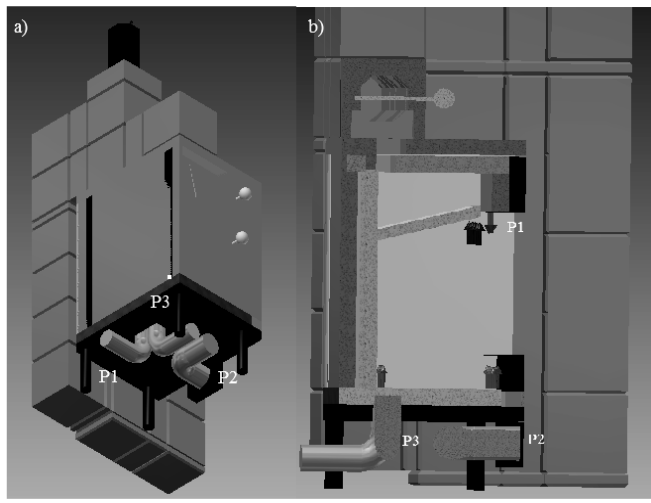

Rys. 3.Wizualizacja kanałów (p1, p2 i p3) doprowadzających powietrze do komory spalania, a) widok od dołu, b) widok z boku

Fig. 3. Visualization of ducts (p1, p2 and p3) delivering air to the combustion chamber, a) bottom view, b) side view

\subsection{Procedura badawcza}

Pomiary opisywane w niniejszym opracowaniu wykonywane były dla ustalonej wielkości wsadu paliwa do komory spalania piecokominka - $8 \mathrm{~kg}$ drewna, przy czym stosowano paliwo o różnej wielkości (grubości) i różnej wilgotności. Próbki paliwa pobierane były do analizy technicznej i elementarnej (m.in. wyznaczona została wartość opałowa), dla kilku próbek przeprowadzono pełną 
analizę TGA/DT. Przygotowanie stanowiska polegało na wcześniejszym spaleniu w piecokominku ustalonej wielkość paliwa (ok. 2-3 kg), aby uniknąć niereprezentatywnego rozpalania i spalania paliwa w zimnym piecokominku.

\section{Wyniki badań}

Wyniki przykładowych badań zostały przedstawione na kolejnych rysunkach. Wyznaczona została generowana moc wskutek ubytku paliwa, przy założeniu, że całkowity ubytek paliwa związany jest z jego termochemiczną konwersją. Wynik został przedstawiony na rysunku 4.

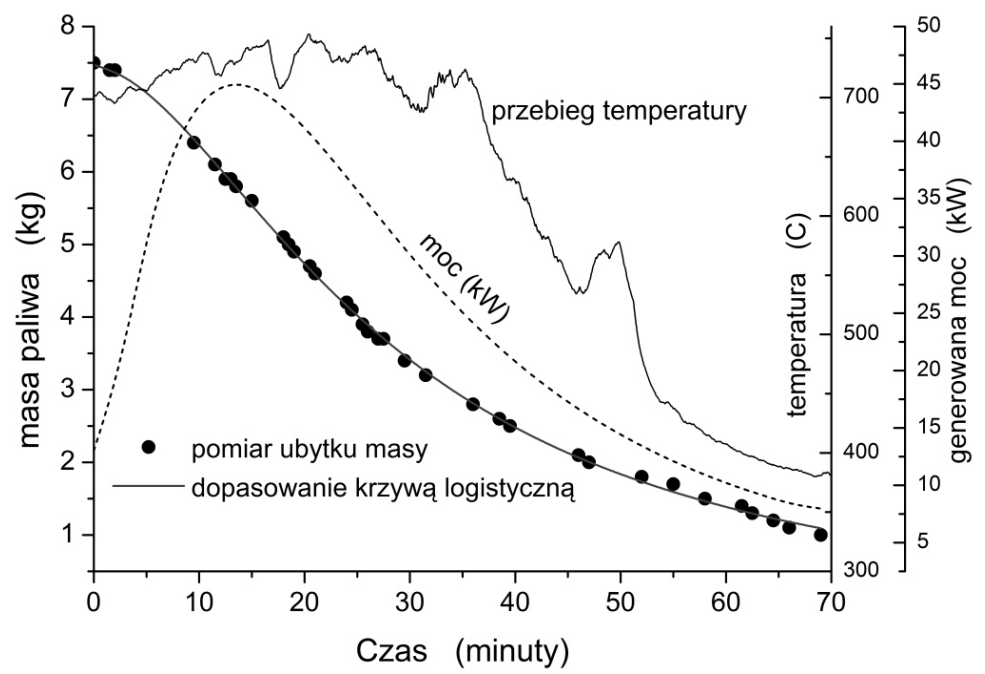

Rys. 4. Przebieg ubytku masy paliwa, mocy grzewczej oraz temperatury w komorze spalania

Fig. 4. Fuel mass losses, heat power and temperature during the combustion

Widoczne jest, że w trakcie spalania, paliwo ubywa z różną intensywnością. Bieżąca masa paliwa $m(\tau)$ może być opisana zależnością, tzw. funkcją logistyczną:

$$
m(\tau)=\frac{m_{0}}{1+\left(\tau / \tau_{0}\right)^{p}}+m_{1}
$$

gdzie $m_{0}, m_{l}, \tau_{0}$ i $p$ to zmienne dopasowania. Parametry $m_{0}, m_{l}$ mają jednostkę masy i można je interpretować jako wielkości dające masę początkową - wkład spalania oraz pozostałość po spaleniu (popiół). Parametr $p$ określa szybkość zachodzenia procesu spalania i może być zależny np. od intensywności dostarczania powietrza czy jakości paliwa. Czas $\tau_{0}$ jest to czas po którym nastąpi ubytek połowy masy $m_{0}$. Dla przykładu przytoczonego na rysunku 5, $\tau_{0}=28.4 \pm 0.5 \mathrm{~kg}, \mathrm{p} 0=1.73 \pm 0.04$. 
Znając ubytek masy możemy wyznaczyć teoretyczną moc piecokominka:

$$
P(\tau)=Q \cdot \frac{d m}{d \tau}
$$

gdzie: $Q$ to zmierzone ciepło spalania próbek użytego drewna, równe 16200 $\mathrm{kJ} / \mathrm{kg}$.

Oczywiście przytoczone zależności mają charakter przybliżony, gdyż zakładają, że ubytkowi masy towarzyszy cały czas ten sam efekt cieplny, a wiadomo, m.in., że w pierwszym etapie spalania zachodzi dosuszanie paliwa, a w końcowym wyżarza się powstały węgiel drzewny.

Rysunek 5 przedstawia zależności temperatury w komorze spalania i stężenia $\mathrm{CO}$ w zależności od ustawienia przepustnic $p 1$ i $p 2$.

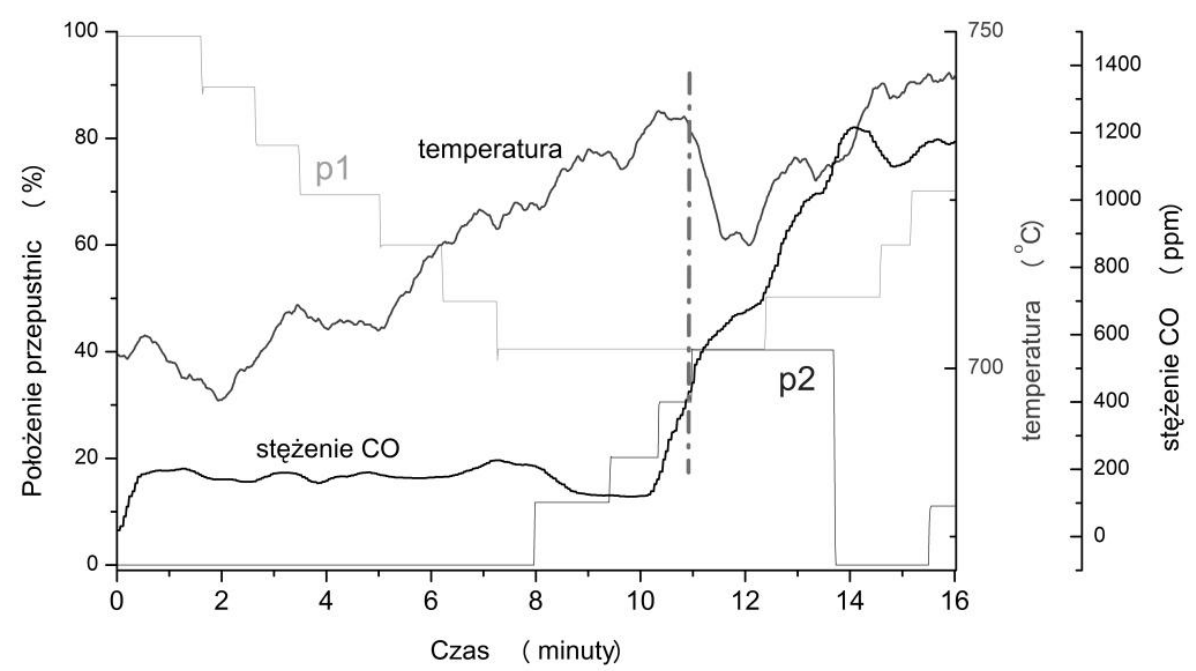

Rys. 5. Przebiegi podstawowych wielkości dla pierwszych 16-tu minut pracy piecokominka

Fig. 5. Values of basic parameters for first 16 minutes of the fireplace operation

Widoczne jest, że w momencie rozpalenia się paliwa temperatura szybko osiągnęła wartość $700^{\circ} \mathrm{C}$, wtedy zaczyna się spalanie zasadniczego wsadu paliwa. Przy zmniejszaniu kąta otwarcia przepustnicy pl od wartości 100\% (pełne otwarcie) do $40 \%$ otwarcia, co nastąpiło w ok. 4.5 minucie nie widać zmian procesu spalania. Temperatura utrzymuje się na poziomie ok. $700^{\circ} \mathrm{C}$, stężenie CO też jest stabilne (ok. 200 ppm). W 8-mej minucie nastąpiło otwarcie przepustnicy $p 2$. Widoczne jest, że niewielkie otwarcia przepustnicy $p 2$ (od 0-20\%) dały korzystny efekt - temperatura nieznacznie wzrosła, a stężenie CO spadło. Kulminacja tego efektu nastąpiła ok. 10-tej minuty. Dalsze zwiększanie stopnia otwarcia przepustnicy $p 2$ przyniosło efekt odwrotny - temperatura nieznacznie spadła, a stężenie CO zaczęło szybko rosnąć. Moment ten oznaczony został pionową przerywaną linią. Nastąpiło to pomimo zwiększenia dostępu powie- 
trza. Dokładne obserwacje pokazują, że ten efekt związany jest z wychłodzeniem obszaru spalania poprzez wprowadzenie zbyt dużej ilości zimnego powietrza - spalanie następuje przy mniejszej temperaturze, co przesuwa równowagę reakcji w stronę tworzenia CO.

W dalszym etapie spalania przedstawionym na rysunku 6 widoczne są następujące zmiany:

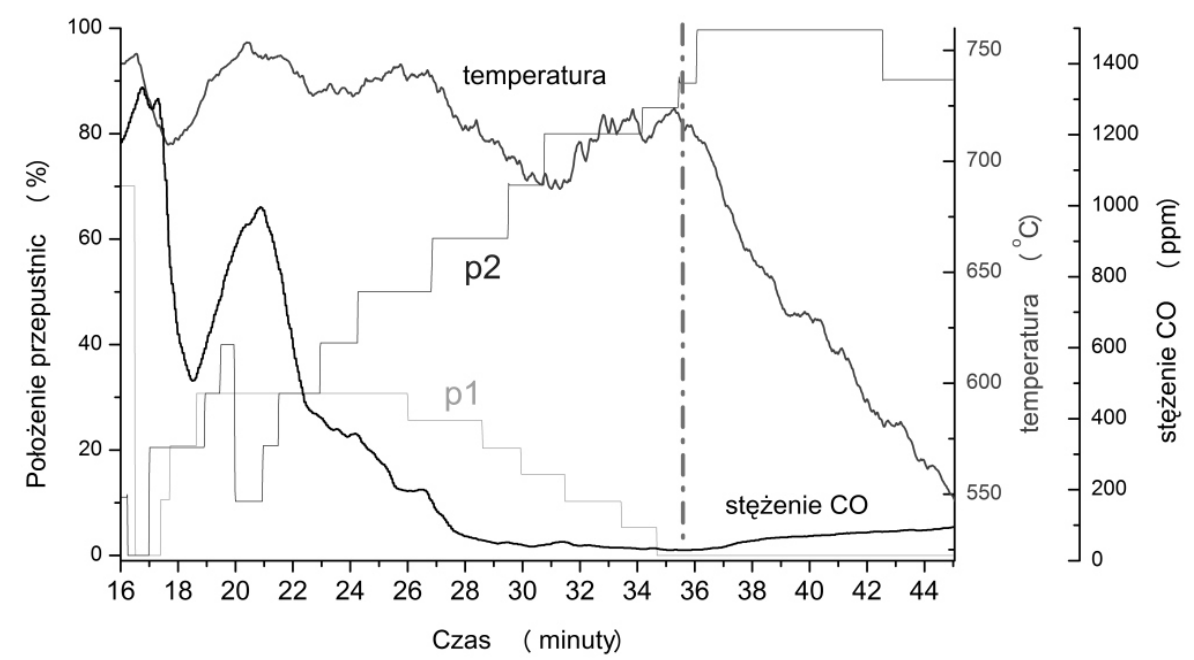

Rys. 6. Przebiegi podstawowych wielkości dla okresu 16-45 minuty pracy piecokominka

Fig. 6. Values of basic parameters for period 16-45 minutes of the fireplace operation

Poprzez zmniejszanie przepływu powietrza przepustnicą pl i zwiększanie przepływu poprzez $p 2$ udało się doprowadzić do rozpoczęcia spadku stężenia CO. Spadek zaczął następować w momencie gdy otwarcie $p l$ wynosiło ok. 30\% a $p 2$ ok. $15 \%$. Dalsze zmniejszanie otwarcia p1 i zwiększanie otwarcia $p 2$ powodowało spadek stężenia CO. Wartość minimalna została osiągnięta w ok. 36 minucie dla $p 1$ bliskiego zero i $p 2$ ponad $80 \%$. Niestety takie otwarcie $p 2$ (a potem jeszcze zwiększenie) spowodowało zbyt duży napływ powietrza i wychłodzenie paleniska - temperatura zaczęła spadać, spowodowało to, że stężenie $\mathrm{CO}$ zaczęło znowu rosnąć. Również całkowite zamknięcie $p 1$ mogło spowodować zmniejszenie podawania powietrza od góry do strefy spalania. Właściwym wydaje się utrzymywanie $p 1$ na poziomie $20 \%$ a $p 2-60 \%$.

$\mathrm{W}$ trakcie prowadzenia procesu spalania badane były widma promieniowania płomienia za pomocą spektrometru. Widmo dla dwóch chwil, tj. 8 i 41 minuty spalania przedstawione jest na rysunku 7. 


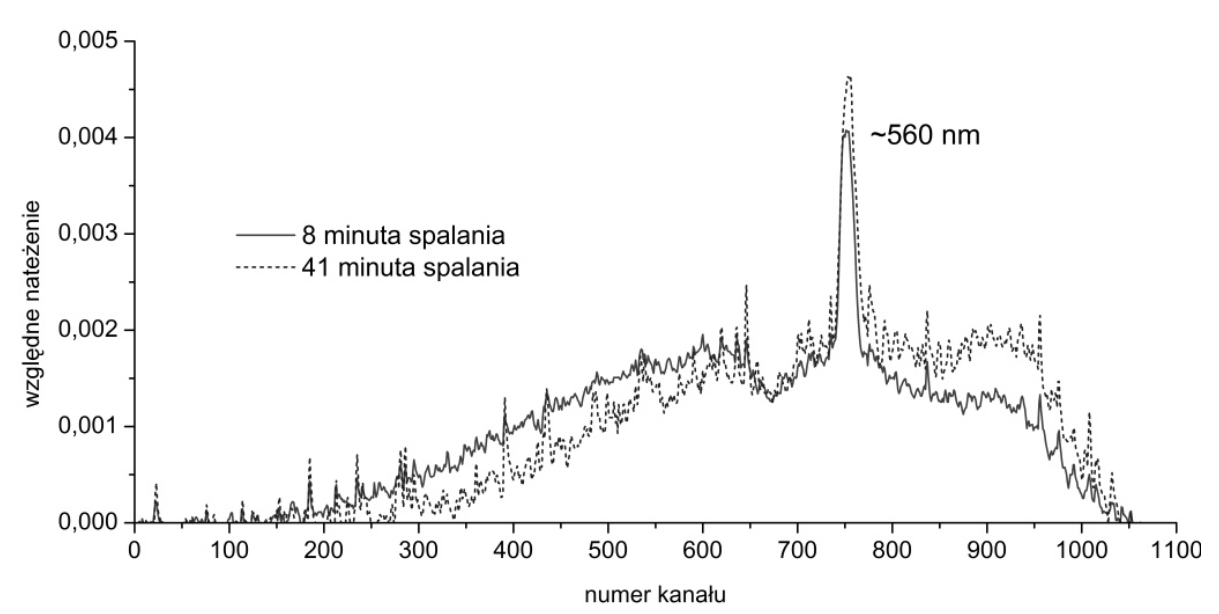

Rys. 7. Znormalizowane widma płomienia dla wybranych chwil pracy piecokominka

Fig. 7. Normalized flame spectra for selected moments of the fireplace operation

Jest to widmo ciągłe sugerujące występowanie w płomieniu cząstek stałych - sadzy, popiołu i innych. Cechą charakterystyczną widma jest występowanie piku dla długości fali ok. $560 \mathrm{~nm}$, sugerującej, że jest to wzbudzone $\mathrm{C}_{2}$. Dla końcowego okresu spalania następuje nasilenie fal powyżej $600 \mathrm{~nm}$ - od świecącego żaru. Za pomocą widma można ocenić fazę spalania i określić np. ilość nagromadzonego żaru oraz określić zapylenie płomienia. Jest to technika badawcza dość intensywnie ostatnio rozwijana jako element diagnostyczny dla dużych jednostek kotłowych.

\section{Podsumowanie i wnioski}

Zamierzeniem opisanych badań jest zwiększenie możliwości sterowania pracą kominka, tak aby uzyskać zarówno optymalizację jego parametrów ekonomicznych, jak i redukcję negatywnego wpływu na środowisko. Przytoczone przykłady pokazują, że $\mathrm{w}$ ten sposób można zebrać istotną wiedzę odnośnie pracy takich układów i zbudować odpowiednie charakterystyki i modele, które posłużą do dalszych prac. Kolejne planowane etapy tych prac to opracowanie odpowiednich algorytmów sterowania, zbudowanie modelu CFD opisywanego urząazenia oraz stworzenie nowatorskiego systemu tzw. raportowania ekologicznego, w którym niektóre $\mathrm{z}$ opisanych powyżej przebiegów będą zdalnie rejestrowane z urządzeń pracujących u użytkowników.

Artykut opracowany $w$ ramach projektu badawczego Województwa Małopolskiego realizowanego przez firmę CEBUD we wspótpracy $z$ WEiP AGH. 


\title{
Literatura
}

[1] M. Filipowicz i inni, „Pomiary podstawowych parametrów pracy piecokominków”, Instal: teoria i praktyka w instalacjach, $\mathrm{nr}$ 6/2014, s.26-33

[2] Materiały firmy CEBUD, www.cebud.eu, ostatni dostęp 22.02.2015

[3] D. Menghini i inni, „Numerical and experimental investigations to lower environment al impact of an open fireplace", Experimental Thermal and Fluid Science, 31(2007)477-482

[4] P. Butschbach i inni, "Extensive reduction of toxic gas emissions of firewood-fueled low power fireplaces by improved in situ gas sensoric and catalytic treatment of exhaust gas", Sensors and Actuators B 137(2009)32-41

[5] F. Ozil i inni, „Efficiency of catalytic processes for the reduction of CO and VOC emission from wood combustion in domestic fireplaces", Fuel Processing Technology 90(2009)1053-1061

\section{STUDY ON ENERGY AND ECOLOGICAL PARAMETERS OF DOMESTIC HEATING APPLIANCES LIKE FIREPLACES WITH HEAT ACCUMULATION}

\begin{abstract}
S u m m a r y
In recent years one can see rapid development of heating systems based on a variety of fuels, different production systems and heat transmission and control systems. These systems, however, have not supplanted the traditional heating devices, represented by stoves, fireplaces, or combinations thereof. Currently, we are witnessing a renaissance of these devices, combining decorative and functional elements, and that can be included to renewable energy biomasspowered. The attention is paid to the best energy parameters and the minimization of harmful factors associated with the combustion of biomass, because more and more popularity gain slogans to prohibit the burning of solid fuels (including biomass). An example might be Kraków. Therefore, AGH, in cooperation with industry, have been working on these devices whereas accurate presentation of their parameters, development of the control systems and, finally, introduce a number of innovations to the work of such traditional sources of energy. Article describes the test bench and presents the results of the first phase of the research. Temperature measurements in the combustion chamber and the exhaust gas system, an analysis of the basic components of the exhaust gases depending on the regulation of the air supply to the combustion chamber were executed. Measurements have been supplemented with the intensity of fuel consumption and the flame spectrum. A collection of results, subjected to appropriate analysis, will allow the development of device's effective control system for maximizing efficiency and minimizing emissions from the furnace.
\end{abstract}

Keywords: fireplace with heat accumulation system, exhaust gases analysis, combustion control, energy efficiency, biomass, wood

Przestano do redakcji: $22.02 .2015 \mathrm{r}$.

Przyjęto do druku: 22.06.2015 r.

DOI:10.7862/rb.2015.37 